such as the preparation of aniline, a-naphthylamine, $m$-phenylenediamine from the corresponding nitrocompounds by reduction with ammonium sulphide, as also the production of azoxybenzene, azobenzene and benzidine by modification or development of the above process.

Butlerov, who succeeded Zinin, is remarkable, not only for his far-reaching researches in the field of structural chemistry and for the introduction of numerous fundamental conceptions now universally employed in the theory of organic chemistry, but also for his influence in forming an entire school of chemists who, up to the present day, have actively followed up and enlarged upon his work. Butlerov's first paper deals with the preparation of trioxymethylene and hexamine, and it was in the course of this work that the first clue to the possible mechanism of sugar synthesis in plants was found, namely, the preparation of a mixture of hexoses from trioxymethylene. In the course of his next investigation on isomerism and isomeric changes, Butlerov suggested the possibility of the phenomenon of tautomerism which was later to occupy so prominent a place in organic chemistry, and incidentally explained the nature and the importance of the zinc methyl reaction, which, as a result of this work, occupied a prominent place in processes of synthesis, until superseded by the Grignard reagent. A further consequence of this work was the demonstration of the possible stability of compounds possessing two hydroxyl groups attached to the same carbon atom, and this was further substantiated by the synthesis of pinacolin from trimethylacetyl chloride. The explanation of the course of reactions of polymerisation in the olefine series must also be attributed to Butlerov, and it is noteworthy that in his investigation on the diisobutylenes he again puts forward the idea of tautomerism.

Among the numerous workers who received their inspiration from Butlerov, perhaps the best known is Markovnikov, the enunciator of the well-known rule which bears his name. His work on the naphthenes is, however, no less important to chemistry than the above rule, and furnishes a classic example of the perseverance and capability of overcoming difficulties so characteristic of Russian chemists. This research, together with those of Wreden at Petrograd and Kijner at Moscow, were instrumental in placing the study of the alicyclic compounds on the same level as that of other hitherto better known substances.

Markovnikov was succeeded in $x 87 \mathrm{I}$ by $\mathrm{A}$. $\mathrm{N}$. Saytzev, who remained as professor of chemistry at Kazan until his death in I909. Much of Saytzev's work was a continuation of his predecessors', dealing with the systematic synthesis of alcohols by the zinc alkyl process. G. Wagner is probably the most brilliant of Saytzev's students. This worker extended Saytzev's method for the preparation of secondary alcohols from ethyl formate by substituting for the latter various aldehydes, thereby obtaining ketones, which served as material for the testing of Popov's rule as to the oxidation of ketones. As a result of this work, Wagner was able to show that this rule did not hold good in all cases, but had to be modified according to circumstances. Following up this research, he next studied the progressive oxidation of compounds possessing ethylenic bindings and showed the importance of oxidation reactions in locating the position of unsaturated linkings in olefinic chains. In this way he was able to assign to oleic acid the structural formula now accepted. A consequence of this work was the view that oxidation of fatty acids occurs in the $\beta$-position, thus anticipating by sixteen years Knoop's theory of $\beta$-oxidation. The application of these oxidation methods to the study of the terpenes occupied the last twelve years of Wagner's life, and enabled him to assign to pinene, terpineol, dipentene, bornyl chloride, bornylene, and camphene their respective formulæ.

Similar work to that of the Kazan school was in the meantime also being carried out at Petrograd, Moscow, and Kiev, where Ipatiev, Zelinski, Favorski, and others studied the reactions of unsaturated hydrocarbons. Ipatiev was the first to synthesise isoprene by a method which gave clear evidence of its structure, and is also known for his work on the structural changes occurring in the unsaturated hydrocarbons obtained by the catalytic dehydration of alcohols. Zelinski investigated the cyclo-paraffins and olefines, whilst Favorski was the discoverer of the change which the homologues of allylene undergo on heating with alcoholic caustic alkalis. Kutcherov was the discoverer of the catalytic conversion of homologues of acetylene into aldehydes and ketones, thus opening the way to the production of acetic acid from carbide.

Mendeléeff is undoubtedly the best known of Russian chemists, and his paper on the periodic classification of the elements is too well known to require description, and the same may be said of the work of Beilstein and Menschutkin.

Prof. Wynne closes with a plea for a better appreciation of the value of the Journal of the Russian Physical-Chemical Society, and suggests that a study of this journal would amply repay the trouble incident on acquiring a sufficient knowledge of Russian.

\title{
The Kerr Effect in Optically Active Liquids.
}

WHEN polarised light passes through an optically active liquid in an electrostatic or a magnetic field the phenomenon of double refraction observed with a non-active substance is complicated by the optical rotation, and the only method employed to study the birefringence has been to mix equal quantities of right- and left-handed samples of the compound to be investigated, so as to obtain a nonactive liquid. M. R. de Mallemann, in the Annales de Physique for July-August, making use of the AiryGouy principle that on the element of path dl the double refraction and the rotation act independently of one another, and that the resultant effect can be calculated by compounding the elementary vectors representing the two effects, derives formulæ by means of which the true double refraction of the liquid can be derived from the observations. Measurements are described on pinene, turpentine, ethyl tartrate, carvone and camphor, in which Panthener's method of instantaneous charge was used, which, in spite of certain difficulties, gives fairly satisfactory results in all cases, and enables the birefringence of imperfect insulators to be determined.

In almost all cases the Airy-Gouy principle gives, qualitatively, the relation between the phenomena; and, in general, there is quantitative agreement even with bodies like carvone, which have very large birefringence, the calculated ellipticities not differing in the majority of cases from those observed by amounts exceeding the limits of precision of the measurements. For the rotation of the axes, however, the differences in the case of carvone are more systematic.

M. de Mallemann considers the theories of Stark, NO. 2870 , VOL. I I 4 ] 
Oseen and Born, in connexion with his own previous work, which explained optical activity in terms of the asymmetry of the molecule; he does not, like the above authors, assume resonance, but uses the single idea of the asymmetry of the field of force, taking into account the experimental data. The theory indicates, in apparent agreement with observation, that the rotary power should increase when the number of atoms is large, when the masses and atomic volumes are large, and when the atoms are arranged very unsymmetrically. It also shows that the rotary dispersion is related to the refractive dispersion; and the specific rotary power should, in general, diminish with increase of temperature, and should increase with the pressure. There are, however, certain discrepancies in passing from the liquid state to that of vapour. Modifications of the molecular structure due to lack of rigidity of the molecule, which would not affect the refractive index, may produce marked changes in the optical activity, and the rotary power must be a very delicate index of molecular phenomena. This accounts for the difficulty of finding simple laws connecting the phenomenon as observed in different substances. The theory indicates that the Airy-Gouy formula can no longer hold rigorously for high refractivity; apparently this commences to be true in the case of carvone.

\section{Engineering and Shipbuilding.}

$\mathrm{T} T$ is not easy to state reasons for the present depression in the engineering and shipbuilding trades without touching upon political matters, and both Mr. J. Howden Hume and Mr. Tom Westgarth found this difficulty in their presidential addresses to the Institution of Engineers and Shipbuilders in Scotland and the North-East Coast Institution of Engineers and Shipbuilders respectively. Still in both addresses there is much of interest and several valuable suggestions.

Mr. Hume attributes the depression to $(a)$ the loss of our export trade; $(b)$ the Washington Treaty, which has seriously affected not only workmen engaged in engineering and shipbuilding, but also those on the technical and scientific staffs, and those connected with allied trades, besides the artisans in districts where warship building was carried out; (c) the world's market on the merchant shipping side has partially collapsed, and there was over-production of merchant ships during and immediately after the War.

Mr. Hume suggests (i.) that the whole question should be taken out of the political field and placed in the hands of a representative body, chosen; say, by half-a-dozen of the leading judges, and comprising equal numbers of manufacturers, workmen, merchants, and professional men. Such a body would arrive at the truth, and a plan could be devised and acted upon by the Government in power. (ii.) A complete and friendly understanding between employer and employed. The Shipping Federation and the National Sailors' and Firemen's Union have worked together for thirteen years, and in that time there has been no strike in the shipping trade. Other bodies might follow this lead.

The subject of Mr. Westgarth's address was waste. Of all sources of waste in industry, the greatest is that caused by strikes and lockouts, by demarcation difficulties between trades, and by people of all classes not doing a fair day's work for a fair day's pay. Many disputes are the result of neglect and delay in dealing with difficulties as they arise, and something of the old-fashioned discussion between master and workmen immediately a difficulty appears should be revived. Such discussion should be informal and not binding on the official representatives of either side, By this method a great many disputes would probably never be taken outside the works. In I $921,85,872$, ooo working days were lost through disputes, and I0,642,000 in I923, according to the Ministry of Labour Gazette. Nearly all this waste is preventable, and could be prevented by friendly conference. Sir Robert Hadfield's suggestion that an endeavour should be made to arrange an industrial truce is worthy of the most serious consideration.

Mr. Westgarth referred to a fruitful cause of unrest wages in the so-called protected trades do not compare reasonably with those in the highly skilled and competitive trades. If competition in the open markets of the world makes it impossible to pay skilled workmen a certain wage, it is in the highest degree wasteful to pay considerably higher wages to unskilled men just because a stoppage of their work would be an inconvenience to the public. This really amounts to a kind of blackmail, and the public should be assisted in resisting such claims by their governing representatives.

In reference to technical waste, Mr. Westgarth says that the engineering industries can only be successfully conducted nowadays by helping to make possible the discovery of new methods of manufacture and fostering the advancement of new ideas in engineering science-as distinct from teaching engineering science -and then by giving commercial expression to the best of such methods and ideas. Has such a policy been characteristic of British engineering? The future of British engineering will be good or bad according as the spirit of scientific progress develops or flags.

\section{Electrical Precipitation. ${ }^{1}$}

THE two kinds of electrical precipitation dealt with were the natural and the artificial. Artificial precipitation began with the well-known experiment which Sir Oliver Lodge showed to the British Association at Montreal in $\mathbf{1} 88_{4}$ on the electrical deposition of smoke or steam; an observation which has now been applied on a large scale in Great Britain, by his sons and by Dr. Cottrell in the United States, to the recovery of metallic fume, and to the freeing of blastfurnace gas from solid material before combustion. The theory of the action is like that of the coherer, and was considerably elucidated by the late Lord Rayleigh's experiments on the cohesion of liquid jets and drops, under slight electrical stimulus.

The natural kind of electrical precipitation is what occurs in the atmosphere when clouds turn into rain; and also when, as shown by Dr. G. C. Simpson, large water-drops break up in a column of ascending air, giving rise to separation of electricities and the phenomenon of thunderstorms. This mode of generating electricity is somewhat surprising. A theory of it is suggested by the coherer and water-drop experiments; since the breaking-up of a drop may be regarded as the converse action to the cohesion of two drops. Electrical infiuence stimulates cohesion: it is possible that absorption may give rise to electrical separation. Not that the two fragments become oppositely electrified, but because the uniting electronic layer is blown away by the air, thus carrying away a negative charge and leaving the residual water positive. Calculation applied to this phenomenon seems to give results of the right order of magnitude, making use of Dr. Simpson's measurements of the charge which can thus be imparted to the fragments

1 Abstract of an address by Sir Oliver Lodge, F.R.S., delivered on Wednesday, October 29, to the Institute of Physics. 